\title{
GPS detection of the instantaneous response of the global ionosphere to strong magnetic storms with sudden commencement
}

\author{
Edward L. Afraimovich, Eugene A. Kosogorov, Ludmila A. Leonovich, \\ Oleg S. Lesyuta and Igor I. Ushakov \\ Institute of Solar-Terrestrial Physics SD, Russian Academy of Science, Irkutsk, Russia
}

\begin{abstract}
Using a new technology for global GPS detection of ionospheric disturbances, GLOBDET, it has been established that a drastic increase in the time derivative of the magnetic field strength during magnetic storms is accompanied by an almost simultaneous decrease in mid-latitude total electron content on the entire dayside. The corresponding correlation coefficient is not below -0.8 ; the delay with respect to the time of a magnetic storm sudden commencement is about 3-10 min. This is most pronounced for magnetic storms with a wellmarked sudden storm commencement. The sudden storm commencements presented in the paper were observed during the initial storm phase. The analysis reported here was made for a set of from 90 to 300 GPS stations for 10 days in 1998-2001 with a different level of geomagnetic activity ( $D s t$ from $-6 \mathrm{nT}$ to $-295 \mathrm{nT}$, and $K_{p}$ from 0 to 9 ). The «simultaneous» total electron content response for the events under consideration was 0.1-0.4 TECU, and the travel velocity of the disturbance from the dayside to the nightside was in the order of $10-20 \mathrm{~km} / \mathrm{s}$. Results obtained are consistent with earlier ionospheric parameter measurements obtained using high temporal resolution methods.
\end{abstract}

Key words global ionospheric response - sudden storm commencement - magnetic storms

\section{Introduction}

The ionospheric response to a Sudden Storm Commencement (SSC) should be set off from the large number of phenomena observed during different phases of magnetospheric storm

Mailing address: Prof. Edward L. Afraimovich, Institute of Solar-Terrestrial Physics SD, Russian Academy of Sciences, P.O. Box 4026, Irkutsk, 664033, Russia; e-mail: afra@iszf.irk.ru development. Many morphological research efforts have been made to puzzle out the dynamic nature of the processes accompanying SSC. SSC response characteristics in mid-latitude VLFemissions were considered in Mullayarov and Muzlov (2000). Observations of post-SSC ionospheric fluxes and particle precipitation events were presented in Nielsen and Honary (2000). The solar wind velocity and density effects on the cyclic behavior of the SSC occurrence frequency were investigated in Makarov (1994).

Distinctive decreases in maximum ionization $\left(N_{m}\right)$ and in ionization at fixed levels $\left(N_{h}\right)$ after SSC were observed for a strong magnetic storm of July 11-19, 1959 (Potapova and Shapiro, 
1961). A valley in the diurnal variation of the $F_{2}$-layer critical frequency $\left(f_{0} F_{2}\right)$, and a drastic increase in the height of the $F_{2}$-layer maximum $\left(h_{\max } F_{2}\right)$ occurred almost simultaneously with SSC on the entire day-side (for mid-latitude stations). The valleys during evening SSC are hidden by an abrupt diurnal change in the parameter $f_{0} F_{2}$; therefore, a scatter of the delay time $\tau$ between the $f_{0} F_{2}$ minimum and the SSC time was observed. The duration $(\Delta T)$ of the $f_{0} F_{2}$ response to the $\mathrm{SSC}$ varied from 1 to $22 \mathrm{~min}$.

Table I presents the following characteristics: magnetic storm date; reference to a relevant publication; $\tau$ - delay between the SSC time and the ionospheric response; $\Delta T$ - duration of the ionospheric response to the SSC; $\Delta|A|$ amplitude increment relative to quiet values; $V$ - displacement velocity of disturbances, and $n$ largest number of stations involved in the investigation.

The post-SSC ionospheric response for the magnetic storm of June 15, 1965 was investigated in great depth by Shashunkina (1968, 1972), based on data from a number of ionospheric stations located at different sites of the globe. Using data on $f_{0} F_{2}$, the $F_{2}$-layer maximum electron density $\left(N_{\max } F_{2}\right)$, the maximum height $h_{\max } F_{2}$, the $F_{2}$-layer thickness $y_{m}$, and electron density distribution profiles with height $\left(N_{h}\right)$, it was found that the delay of the maximum of the ionospheric response to $\mathrm{SSC}$ varied from 0 to $90 \mathrm{~min}$. The response duration according to $f_{0} F_{2}$ data varied from 90 (low solar activity) to $180 \mathrm{~min}$ (high solar

Table I. Characteristics of the ionospheric response to SSC.

\begin{tabular}{|c|c|c|c|c|c|c|c|c|c|}
\hline $\mathrm{N}$ & Date & Reference & Technique & Parameters & $\tau, \min$ & $\Delta T, \min$ & $\Delta|A|$ & $\mathrm{V}, \mathrm{m} / \mathrm{s}$ & $\mathrm{n}$ \\
\hline 1 & 11-19.07-1959 & $\begin{array}{l}\text { Potapova and Sphiro } \\
\text { (1961) }\end{array}$ & $0 \quad \mathrm{I}$ & $\begin{array}{c}f_{0} F_{2}, N(h) \\
N_{\mathrm{m}} F_{2}, N_{h}\end{array}$ & $0-138$ & $1-22$ & $0.2-2 \mathrm{MHz}$ & - & 14 \\
\hline 2 & 15.06 .1965 & $\begin{array}{l}\text { Shashunkina } \\
(1968,1972)\end{array}$ & I & $\begin{array}{c}f_{0} F_{2}, N(h) \\
h_{\mathrm{m}} F_{2}, N_{\mathrm{m}} F_{2}, \\
h^{\prime} F_{2}, y_{\mathrm{m}}\end{array}$ & $0-90$ & $90-180$ & $1-1.3 \mathrm{MHz}$ & $0.72-2.5$ & 20 \\
\hline 3 & $25-26.05 .1990$ & $\begin{array}{c}\text { Buonsanto } \\
(1995)\end{array}$ & $\begin{array}{c}\text { FRLPS, } \\
\text { ISR }\end{array}$ & $\begin{array}{c}\text { TEC, } N_{\mathrm{m}} F_{2}, \\
h_{\mathrm{m}} F_{2} \\
\end{array}$ & $\begin{array}{l}108-300 \\
180-300 \\
\end{array}$ & $102-360$ & $\begin{array}{c}10-32 \text { TECU, } \\
150 \mathrm{~km} \\
\end{array}$ & - & $\begin{array}{c}4, \\
1 \\
\end{array}$ \\
\hline 4 & $25-26.09 .1958$ & Rüster (1965) & $\mathrm{I}$ & $h_{\mathrm{m}} F_{2}, f_{0} F_{2}$ & 150 & 120 & $100 \mathrm{~km}$ & - & 1 \\
\hline 5 & $13-14.09 .1959$ & Rüster (1965) & $\mathrm{I}$ & $h_{\mathrm{m}} F_{2}$ & 180 & 120 & $150 \mathrm{~km}$ & - & 1 \\
\hline 6 & $3-4.10 .1959$ & Rüster (1965) & I & $f_{0} F_{2}$ & 90 & 90 & $100 \mathrm{~km}$ & - & 1 \\
\hline 7 & 8.07 .1958 & $\begin{array}{c}\text { Bowman } \\
(1965) \\
\end{array}$ & I & $\begin{array}{c}\Delta h^{\prime} F \\
h_{\mathrm{m}} F_{2}\end{array}$ & $3-3.5$ & $180-540$ & $20-100 \mathrm{~km}$ & $0.37-0.72$ & 5 \\
\hline 8 & $12-14.03 .1989$ & $\begin{array}{l}\text { Huang and Cheng } \\
\text { (1991) }\end{array}$ & $\begin{array}{l}\text { g I } \\
\text { FRLPS } \\
\end{array}$ & $f_{0} F_{2}$, TEC & $0-0.6$ & $30-60$ & $\begin{array}{c}5 \mathrm{MHz}, \\
65 \mathrm{TECU}\end{array}$ & - & $\begin{array}{l}1, \\
3\end{array}$ \\
\hline 9 & $\begin{array}{c}\text { 15.02.1967; } \\
13.03 .1970 \\
\end{array}$ & $\begin{array}{l}\text { Huang et al. } \\
\text { (1973) }\end{array}$ & FDS & $\Delta f$ & $0-0.07$ & $1-4$ & $0.5-2 \mathrm{~Hz}$ & - & 2 \\
\hline 10 & $\begin{array}{c}\text { 6.01.1998; } \\
\text { 23.04.1998; } \\
\text { 6.04.2000; } \\
\text { 8.06.2000; } \\
\text { 13-15.07.2000; } \\
\text { 31.03.2001; } \\
\text { 4-11.04.2001 }\end{array}$ & - & GLOBDET & TEC & $4-10$ & $15-30$ & $0.08-0.38$ & $10-209$ & $90-300$ \\
\hline
\end{tabular}

I = ionosonde; FRLPS = Faraday rotation of the linearly-polarized signal; ISR = incoherent scatter radar; FDS $=$ frequency Doppler shift measurements along the HF path; 1TECU $=10^{16} \mathrm{~m}^{-2}$. 
activity) depending on the station's latitude. The delay of the ionospheric response to SSC increased from high to low latitudes.

Some publications (Huang and Cheng, 1991; Buonsanto, 1995) contain estimates of variations of ionospheric parameters after SSC made on the basis of data from Incoherent Scatter Stations (ISS) and by determining the value of the Total Electron Content (TEC) from Faraday effect measurements of the signal from geostationary satellites (GOES2, GOES7). The delay of the ionospheric response to SSC for the magnetic storm of May 25-26, 1990 was 108-300 min (according to TEC measurements) and 180-300 min (according to data from ISS) (Buonsanto, 1995). The response duration $\Delta T$ was $102-360$ min. For the magnetic storm of March 12-14, 1989, $\tau$ ranged from 0 to $36 \mathrm{~min}$ according to TEC and $f_{0} F_{2}$ data. The response duration $\Delta T$ was 30-60 min (Huang and Cheng, 1991).

Information on the ionospheric response to SSC for the magnetic storms of September 2526, 1958, September 13-14, 1959, October 3-4, 1959, and July 8, 1958 according to ionosonde data is reported by Bowman (1965) and Rüster (1965). The delay $\tau$ for these storms averaged 90-210 min. The ionospheric response to an instantaneous change in the magnetic field lasted 90-540 min.

The ionospheric response to a SSC of the magnetic storms of February 15 and September 19, 1967; October 29, 1968; May 14, 1969; April 28, 1969, and of March 31, 1970, was investigated by measuring the frequency Doppler shift along an HF path (Huang et al., 1973). The delay $\tau$ between a maximum frequency Doppler shift and the SSC time was 0-4 min; the response duration was 1-4 min. Of all the abovementioned data these results are distinguished for the highest time resolution and hence for the highest reliability of determination of the response delay $\tau$.

Investigations of the ionospheric response to SSC made by a number of authors to date, contributed significantly to the study of the phenomena described above. A demerit characteristic for most investigations is the low spatial and temporal resolution of measuring facilities (time steps of 5 or $15 \mathrm{~min}$; the largest number of ionospheric stations involved in the study of the same event does not exceed 20). For that reason, in spite of the large body of experimental evidence available, it is impossible to obtain reasonably reliable estimates of the main parameters of ionospheric response to SSC.

Because of this, the results presented in table I are most likely to refer to different manifestations of geomagnetic disturbances in the mid-latitude ionosphere. Thus, in some cases (lines 2 and 7 of table I) the ionospheric parameter variations were caused by large-scale traveling ionospheric disturbances (LS TID) with typical time periods of 1-2 $\mathrm{h}$ and wavelengths in the order of 1000 km (Bowman, 1965; Shashunkina, 1968, 1972). It is generally believed that LS TIDs are manifestations of Acoustic-Gravity Waves (AGW) whose generation regions lie in equatorial zones of the northern and southern hemispheres. These concepts received further support through recent experiments using GPS data (Ho et al., 1998; Afraimovich et al., 2000b). The LS TID response delay of about $1-2 \mathrm{~h}$ is consistent with the idea that TIDs are generated in auroral regions and travel equatorward at a velocity of about $300-400 \mathrm{~m} / \mathrm{s}$. In other cases (lines 9 and 10 of table I) the response delay is too small to be consistent with the above mechanism associated with the generation and propagation of AGW.

A global spatial averaging of TEC variation, obtained using data from the international GPS network, seems to have been used for the first time by Afraimovich et al. (2000a) in investigating the global ionospheric response to SSC. An «instantaneous» ionospheric response to a sudden commencement, SSC, of a strong magnetic storm of April 6, 2000 was detected; it appeared as a single negative TEC disturbance with a duration of about $20 \mathrm{~min}$, with about 200 $\mathrm{s}$ delay with respect to the SSC at mid-latitudes, almost simultaneously on the entire dayside. The study reported by Afraimovich et al. (2000a) used the new technology, GLOBDET, developed at the ISTP SD RAS for global detection of ionospheric disturbances of natural and artificial origins using data from the international network of two-frequency multi-channel receivers of the navigation GPS system which substantially improves the sensitivity and space-time resolution of experiment (Afraimovich, 2000). 
The objective of this paper is to obtain statistically more significant estimates of the main parameters of the response to SSC for magnetic storms with a different level of geomagnetic activity. The SSC presented in the paper were observed during the initial storm phase.

\section{The method for determining the global ionospheric response to a sudden storm commencement}

We now outline the procedure of processing GPS data which is directly used in this paper. The input data in our experiment are represented by series of «oblique» TEC values along the beam to the GPS satellite at selected receiving points, as well as the corresponding series of values of the elevation $\theta(t)$ and azimuth $\alpha(t)$ of the beam calculated from our developed CONVTEC program to convert standard (for the GPS system) RINEX-files available through the Internet (Gurtner, 1993).

The variations of the «oblique» TEC $I(t)$ are determined on the basis of phase measurements at each of the spatially separated two-frequency GPS receivers using the known formula from Hofmann-Wellenhof et al. (1992)

$$
\begin{gathered}
I=\frac{1}{40.308} \frac{f_{1}^{2} f_{2}^{2}}{f_{1}^{2}-f_{2}^{2}}\left[\left(L_{1} \lambda_{1}-L_{2} \lambda_{2}\right)+\right. \\
+ \text { const }+n L]
\end{gathered}
$$

where $L_{1} \lambda_{1}$ and $L_{2} \lambda_{2}$ are the increments of the radio signal phase path caused by the phase delay in the ionosphere (m); $L_{1}$ and and $L_{2}$ stand for the number of complete phase rotations, and $\lambda_{1}$ and $\lambda_{2}$ are the wavelengths $(\mathrm{m})$ for the frequencies $f_{1}=1575.42 \mathrm{MHz}$ and $f_{2}=1227.60$ $\mathrm{MHz}$, respectively; const is some unknown initial phase path (m); and $n L$ is the error in determining the phase path $(\mathrm{m})$. The sensitivity of phase measurements in the GPS system permits irregularities and wave processes to be detected over a wide range of amplitudes (as large as $10^{-3}$ of the diurnal TEC variation) and periods (from several days to a few minutes).
Standard data available via the Internet have a time resolution of $30 \mathrm{~s}$. Ionospheric data provide their data with a time resolution of 5-15 min. Hence the GPS data have higher time resolution compared with ionosondes and incoherent scatter stations.

To determine the characteristics associated with disturbances involves selecting several series of TEC $I(t)$ measurements with a duration of $1 \mathrm{~h}$ at least. To exclude the influence of the signal reception conditions, we used only observations with satellite elevations $\theta(t)$ larger than $30^{\circ}$. For the purpose of eliminating the variations of a regular ionosphere as well as trends introduced by the satellite motion, use is made of the procedure of removing the linear trend by preliminarily smoothing the initial series with the selected time window of a duration in the order of $30 \mathrm{~min}$.

The GLOBDET software package used in this study performs a global coherent accumulation of TEC variations over the time interval chosen for the analysis (Afraimovich, 2000)

$$
S(t)=\sum_{i=1}^{n} d I_{i} \times K_{i}
$$

where $d I_{i}$ is the filtered TEC series; and $n$ is the number of beam. The correction coefficient $K_{i}$ is required for converting the «oblique» TEC to an equivalent «vertical» value (Klobuchar, 1997)

$$
K_{i}=\cos \left[\arcsin \left(\frac{R_{z}}{R_{z}+h_{\max }} \cos \theta_{i}\right)\right]
$$

where $R_{z}$ is Earth's radius; and $h_{\max }$ is the height of the ionospheric $F_{2}$-layer maximum.

\section{Geometry of the experiment}

The investigation reported in this paper is based on data from the global network of GPS receiving stations available via the Internet. At present (as of February 2001), data from no fewer than 800 GPS stations can be accessed through the Internet. Figure 1a illustrates the geometry of part of the global network used in 

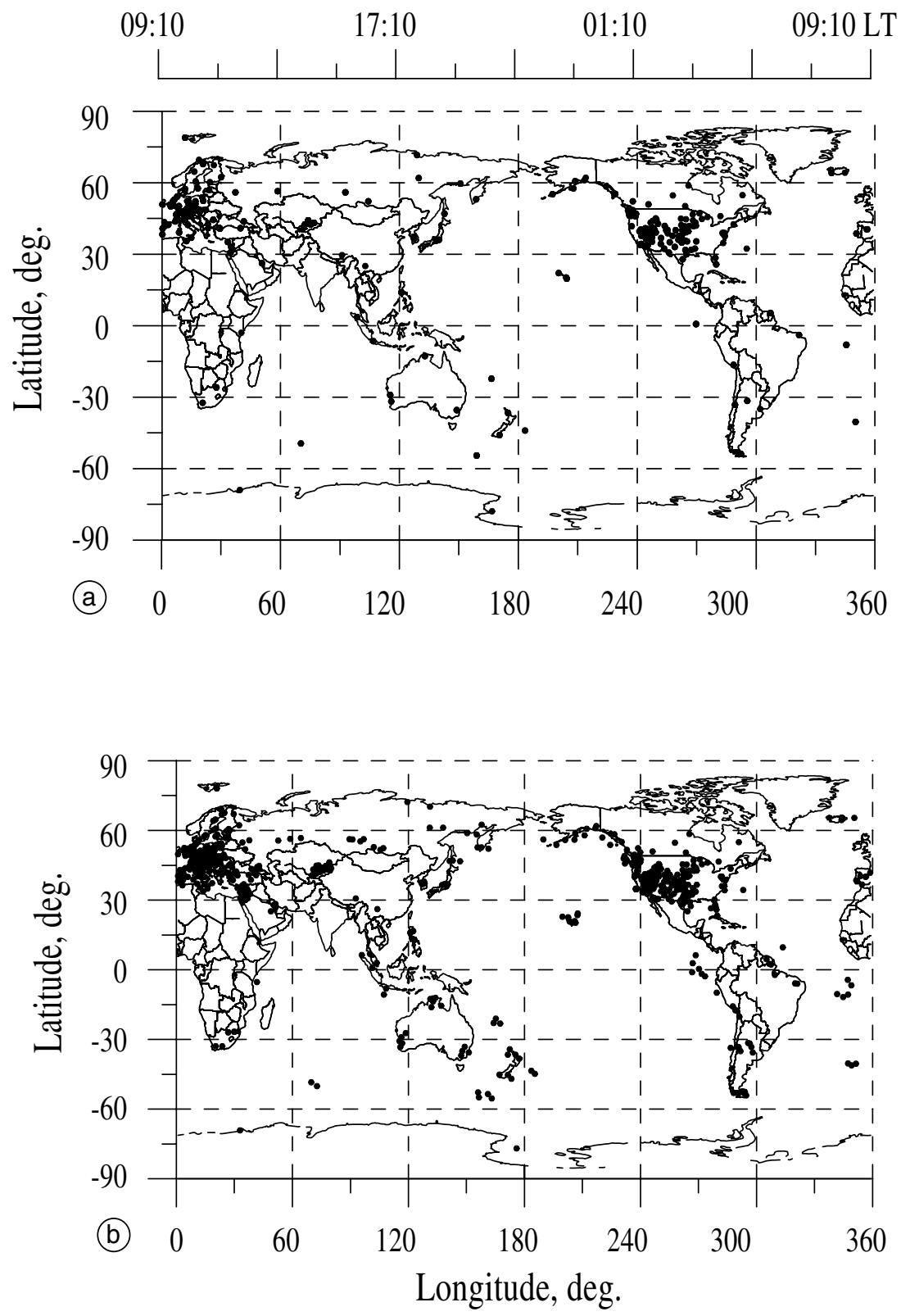

Fig. 1a,b. The geometry of the part of the global GPS network used in this study when analyzing the ionospheric response to the SSC of the strong magnetic storms of June 8, 2000 (263 stations) (a). Dots correspond to the location of GPS stations. The upper scale indicates the local time LT, corresponding to the time 09:10 UT. Panel (b) shows the coordinates of subionospheric points for the height of the $F_{2}$-layer maximum $h_{\max }=300 \mathrm{~km}$ for all satellites visible at the SSC time June 8, 2000, for each of the GPS stations marked on panel a (a total of 1325 LOS). 
this case study of the magnetic storm of June 8, 2000 (263 stations). As is evident from fig. 1a, the set of stations we selected from the part of the global GPS network available to use, covers rather densely North America and Europe, and to a much lesser extent Asia. GPS stations are more sparsely distributed on the Pacific and Atlantic Oceans. However, such coverage of the surface of the globe makes it possible, even today, to tackle the problem of global detection of disturbances with hither to unprecedented spatial accumulation. This ensures the number of statistically independent series which is, as a minimum, by two orders of magnitude larger than could be realized when taking records with other measuring facilities. Thus, in the Western hemisphere the corresponding number of stations can reach no less than 500 today, and the number of beams to the satellite can be no less than 2000-3000. The upper scale in fig. 1a shows the Local Time (LT), corresponding to 09:10 UT (SSC time for the magnetic storm of June 8, 2000).

For a variety of reasons, slightly differing sets of GPS stations were selected for different events to be analyzed; however, the geometry of experiment for all events was virtually identical. The station coordinates are not given here for reasons of space. This information may be found at the electronic address http://lox.ucsd.edu/cgibin/allCoords.cgi?

Figure $1 \mathrm{~b}$ presents the locations subionospheric points for the height $h_{\text {max }}=300 \mathrm{~km}$ for the whole set of GPS satellites during the SSC of June 8, 2000 , for each of the GPS stations marked off in fig. 1a (the number of beams is 1325).

\section{Ionospheric response to a sudden commencement of the strong magnetic storm of April 6, 2000}

Figure 2a-d plots the TEC time dependence $I(t)$ on the dayside for April 6, 2000 (a), and the $d I(t)$ variations obtained upon removing the linear trend from the $I(t)$ series and smoothing with the 30-min time window (b) for stations ALGO (PRN02, thick line) and OHIG (PRN01, thin line). The same applies for the nightside for stations IRKT (PRN21, thick line), KERG
(PRN22, thin line) (c) and (d). As is evident from fig. $2 \mathrm{~b}$, the decrease of $d I(t)$ relative to the SSC time, which is characteristic for the ALGO and OHIG stations, occurs with a delay $\tau$ of about 5 min. For the IRKT and KERG stations (fig. 2d), there is a delay of about 32-37 min between the valley in $S(t)$ and the SSC time.

The geographic coordinates of GPS stations OHIG and ALGO are shown in fig. 2b, and those for stations IRKT and KERG are indicated in fig. 2 d.

For the time interval 16:00-18:00 UT, April 6,2000 , fig. 3a plots the variations in magnetic flux at geostationary orbit of the GOES10 satellite $\left(135^{\circ} \mathrm{W}\right)$, fig. $3 \mathrm{~b}$ the variations of the $H$ component of the magnetic field $H(t)$, and fig. $3 \mathrm{c}$ the time derivative of the $H$-component (thin line) for station Irkutsk $\left(52.20^{\circ} \mathrm{N} ; 104.30^{\circ} \mathrm{E}\right)$. Results of a global summation of $S(t)$ are presented for the dayside (472 trajectories) in fig. $3 \mathrm{~d}$. The dependence $S(t)$ for the nightside (245 trajectories) is plotted in fig. 3e. For comparison, fig. 3c plots the inverted curve $S(t)$ for the dayside (thick line). The SSC time (16:39 UT) in fig. 3a-e is shown by the vertical dashed line.

An analysis of the TEC data for our entire chosen set of GPS points for the time interval 16:30-17:30 UT, including the SSC time, shows a negative disturbance of a duration of about $20 \mathrm{~min}$. The delay $\sigma$ between a maximum of the $d H(t) / d t$ and a maximum of the inverted $S(t)$ series was $6 \mathrm{~min}$. The delay $\tau$ between the SSC time and a maximum of the $S(t)$ curve was $7 \mathrm{~min}$.

Figure $4 \mathrm{a}$ plots the time of a minimum $t_{\min }$ of the filtered TEC series versus latitude, obtained for each beam; the amplitude of the TEC response to the SSC of the strong magnetic storm of April 6, 2000 on the dayside; and the distribution of $t_{\min }$ and of the response amplitude $A$ as a function of Local Time (LT) (for the time interval 16:24-17:36 UT). The SSC time in fig. $4 a, c$ is shown by the thin horizontal line. The scatter of the time $t_{\min }$ is due to the fact that there exist background TEC fluctuations with periods similar to periods of oscillations caused by the $\mathrm{SSC}$; therefore, to improve the signal/noise ratio we apply a global coherent accumulation of $d I(t)$ series. 
April 6, 2000

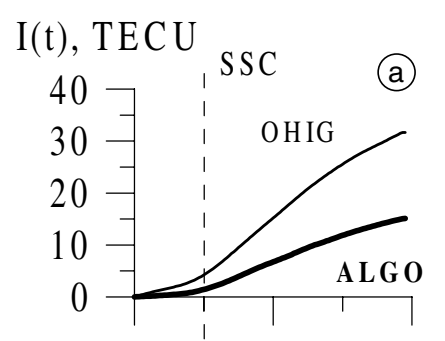

$\mathrm{dI}(\mathrm{t})$, TECU।
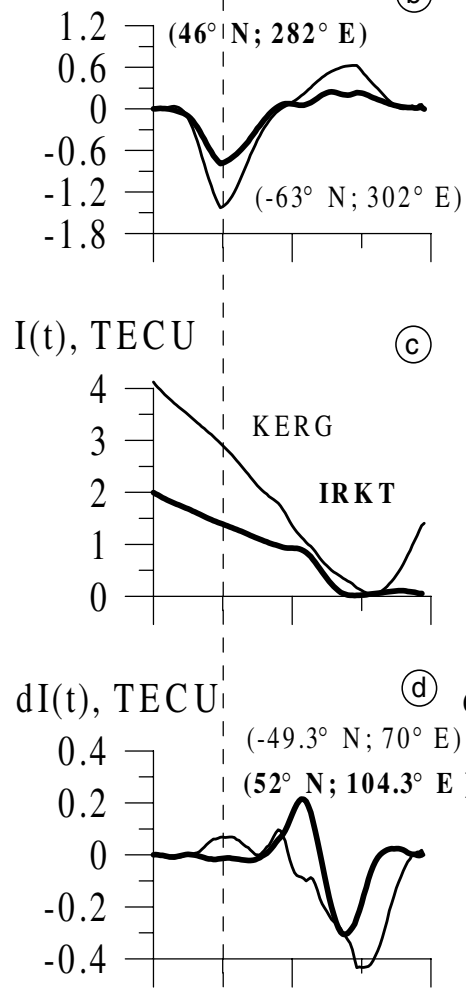

16:30 17:00 17:30

Time, UT
June 8, 2000

$\mathrm{I}(\mathrm{t}), \mathrm{TECU}$

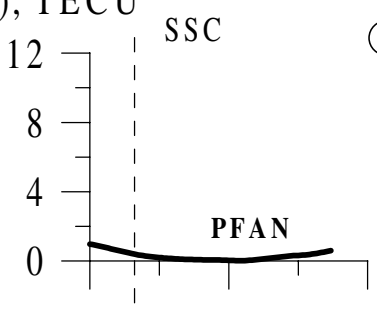

(f)

$\left(47.5^{\circ} \mathrm{N} ; 9.8^{\circ} \mathrm{E}\right)$

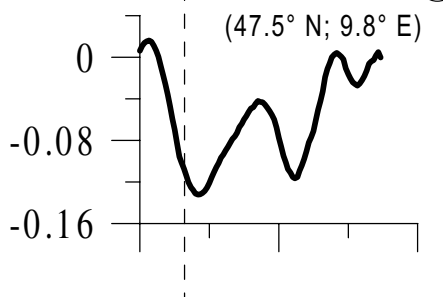

C) $\mathrm{I}(\mathrm{t}), \mathrm{TECU}$

(9)

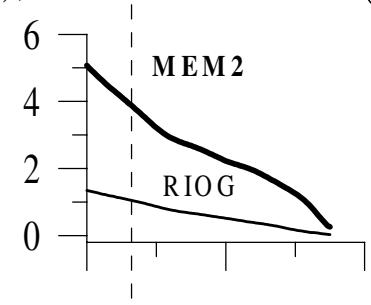

$\mathrm{I}(\mathrm{t})$, TECU

(h)

(e)

)

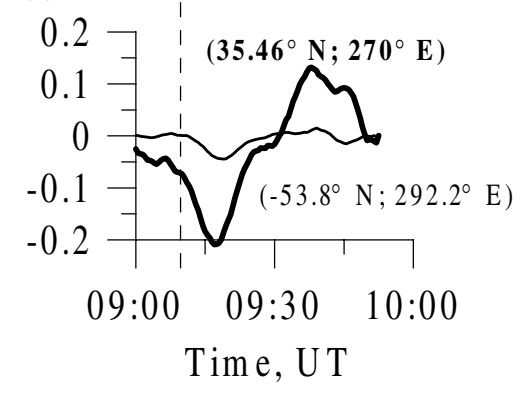

Fig. 2a-h. Time dependencies of TEC $I(t)$ on the dayside on April 6, 2000 (a), and variations of the $d I(t)$ with the linear trend removed and a smoothing with the 30-min time window (b) for stations ALGO (PRN02 - thick line) and OHIG (PRN01 - thin line). Same on the nightside for the station IRKT (PRN21 - thick line) and KERG (PRN22 - thin line) (c) and (d). Time dependencies of TEC $I(t)$ on the dayside on June 8, 2000 (e), and variations of the $d I(t)$ (f) for stations PFAN (PRN03 - thick line). Same on the nightside for the station MEM2 (PRN02 - thick line) and RIOG (PRN01 - thin line) (g) and (h). All panels show GPS station names, PRN numbers of the GPS satellites and geographical coordinates of stations. 


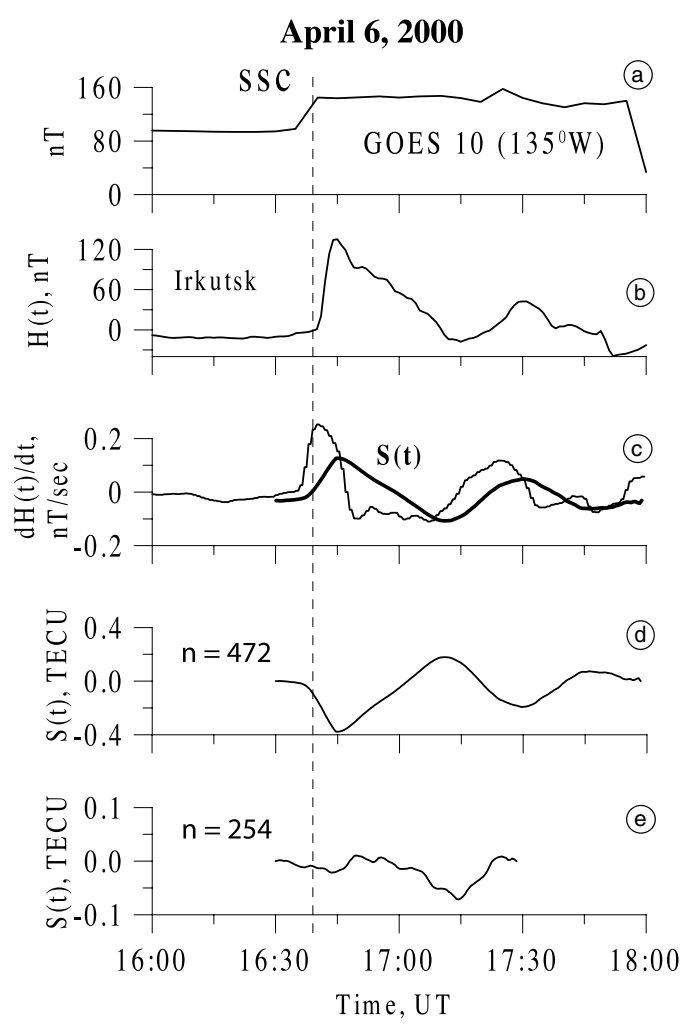

Fig. 3a-e. The variations in magnetic flux (a) at geostationary orbit of the GOES 10 station $\left(135^{\circ} \mathrm{W}\right)$, the variations of the $H$-component of the magnetic field $H(t)(\mathrm{b})$, and of the time derivative $d H(t) / d t$ (c) (thin line) for the time interval 16:00-18:00 UT, April 6,2000 , at station Irkutsk $\left(52.2^{\circ} \mathrm{N}, 104.3^{\circ} \mathrm{E}\right)$. The result of a global spatial averaging of $S(t)$ (d) for 472 LOS on the dayside. A similar result for $245 \mathrm{LOS}$ on the nightside (e). For comparison, panel (c) presents the inverted curve $S(t)$ (heavy line) on the dayside. The time of SSC is shown on panels (a-e) by a vertical dashed line.

An examination of figs. $3 \mathrm{a}-\mathrm{d}$ and $4 \mathrm{a}-\mathrm{d}$, suggests the conclusion that on the dayside of the Earth the largest value of the TEC response amplitude was 0.4 TECU (1-2\% of the background value of the TEC $I_{0} ; 1$ TECU $=10^{16}$ $\left.\mathrm{m}^{-2}\right)$. The value of $I_{0}$ was determined from standard IONEX-files (Mannucci et al., 1998), available via the Internet, by averaging the TEC values for the latitude, longitude and time ranges of our interest. The duration of the ionospheric response to the SSC was $20 \mathrm{~min}$. The delay $\tau$ between the largest value of the TEC response amplitude and the SSC time, in mid-latitudes on the dayside, was $6 \mathrm{~min}$. In high latitudes the delay $\tau$ lasts for more than $15 \mathrm{~min}$. On the nightside, $A=0.1$ TECU, and $\tau=45 \mathrm{~min}$.

\section{Ionospheric response to other magnetic storms}

Similar results were also obtained for some other magnetic storms: of January 6 and April 23, 1998; June 8 and July 13, 14 and 15, 2000; and of March 31 and April 4, 11, 2001. Data on the magnetic field were received from the GOES spacecraft (the satellite numbers are 9 and 10 for April 23, 1998 and June 8, 2001; March 31 and April 4, 11, 2001, respectively).

Figure 2 (right) plots the time dependencies of the TEC $I(t)$ on the dayside for June 8, 2000 (e) and the $d I(t)$ variations (f) for GPS station PFAN (PRN03). The same applies for the nightside for stations MEM2 (PRN02, thick curve) and RIOG (PRN01, thin curve). It is apparent from fig. $2 \mathrm{f}$ that for station PFAN lying on the dayside, the delay $\tau$ between the SSC onset time and a minimum $d I(t)$ is about $3 \mathrm{~min}$. On the nightside, $\tau=7-9$ min for stations MEM2 and RIOG. The geographic coordinates of GPS station PFAN and for stations MEM2 and RIOG are shown in fig. $2 \mathrm{f}$, h respectively.

Figure $4 \mathrm{e}-\mathrm{h}$ shows the same parameters as in fig. 4a-d, but for the magnetic storm of June 8,2000 . The response amplitude $A$ in fig. $4 \mathrm{~h}$ is plotted as a function of Local Time (LT) for the time interval 08:42-09:42 UT.

Figure 5a-e plots the same dependencies as in fig. 2a-h, but for the time interval 08:00-10:00 UT, June 8, 2000. The result of a global coherent summation for the dayside (fig. 5d) is shown for 406 beams. Such a result for $S(t)$ on the nightside (632 beam) is presented in fig. 5e.

Figure 6a-e plots the same dependencies as in fig. 2a-h, but for the time interval 15:30-17:30 UT, April 11, 2001. The result of a global coherent summation for the dayside (fig. $6 \mathrm{~d}$ ) is shown for 403 beams. Such a result for $S(t)$ on the nightside ( 97 beam) is presented in fig. $6 \mathrm{e}$. 
April 6, 2000

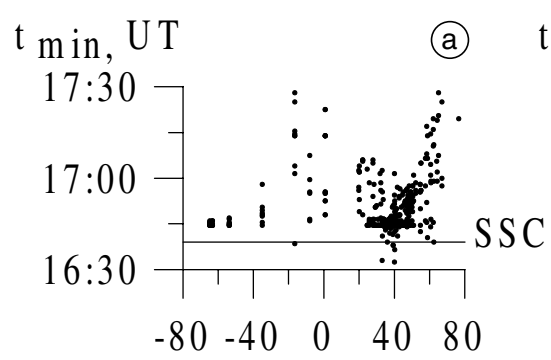

June 8, 2000

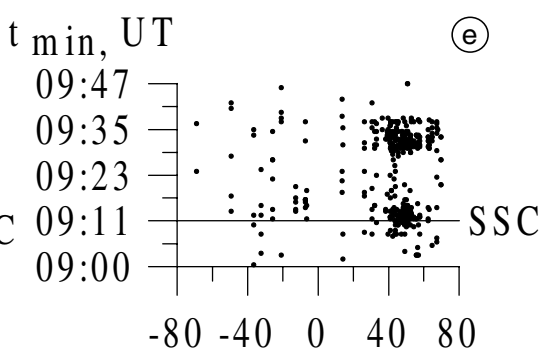

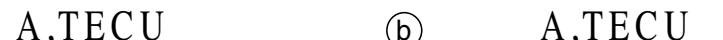
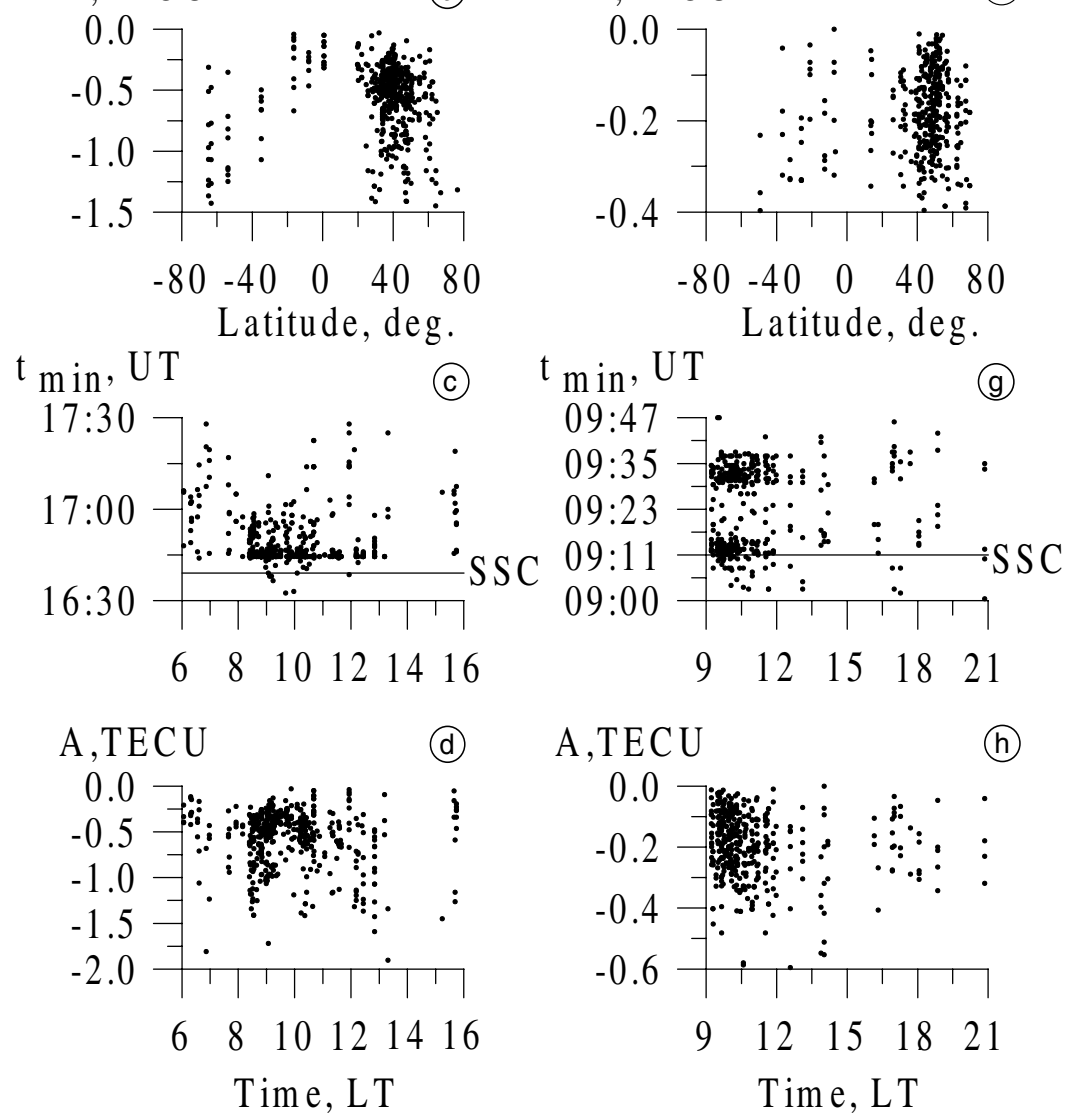

Fig. 4a-h. The latitudinal dependencies (obtained for each LOS) of the $t_{\min }$ (a) and of the amplitude $A$ (b) of the ionospheric response to the magnetic storm SSC on April 6, 2000, on the dayside; the total distributions of $t$. (c) and $A(\mathrm{~d})$ as a function of local time LT (for the time interval 16:24-17:36 UT). The latitudinal dependencies of the $t_{\text {in }}$ (e) and of the amplitude $A$ (f) of the ionospheric response to the magnetic storm SSC on June 8, 2000, on the dayside; the total distributions of $t_{\min }(\mathrm{g})$ and $(\mathrm{h})$ as a function of local time LT (for the time interval 08:42-09:42 UT). The SSC times is shown on panels (a, c, e, g) by a horizontal straight line. 
June 8, 2000
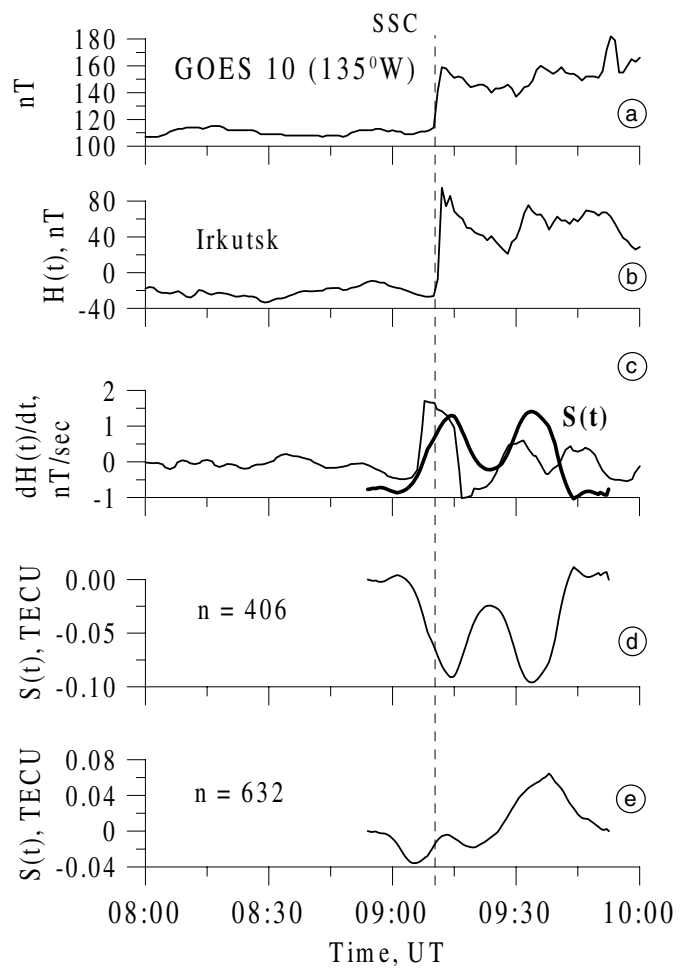

Fig. 5a-e. The same as fig. $2 \mathrm{a}-\mathrm{h}$, but for the time interval 08:00-10:00 UT, June 8, 2000. The result of a global spatial averaging of $S(t)$ for 406 LOS on the dayside (d). A similar result for 632 LOS on the nightside (e).

An examination of figs. $4 \mathrm{a}-\mathrm{h}$ and $5 \mathrm{a}-\mathrm{h}$ suggests that the ionospheric response to the SSC lasted $20 \mathrm{~min}$. The delay $\sigma$ between a maximum of the inverted curve $S(t)$ and a maximum of the curve $d H / d t$ is $3.5 \mathrm{~min}$. The delay $\tau$ between the SSC time and a maximum of the $S(t)$ curve was $4.5 \mathrm{~min}$. On the dayside of the Earth the largest value of the response in amplitude and the delay $\tau$ with respect to the SSC time were 0.1 TECU and $2 \mathrm{~min}$, respectively. On the nightside, these values were 0.06 TECU and $8 \mathrm{~min}$, respectively. The travel velocity of the disturbance from midto high-latitudes and from the dayside to the nightside averaged $10-20 \mathrm{~km} / \mathrm{s}$.
April 11, 2001

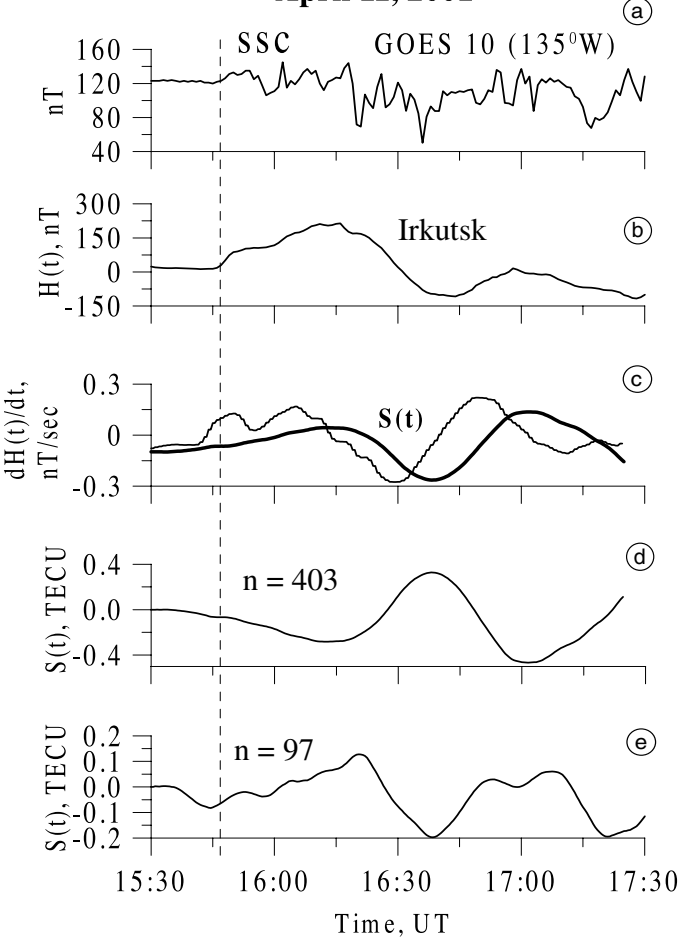

Fig. 6a-e. The same as fig. $2 \mathrm{a}-\mathrm{h}$, but for the time interval 15:30-17:30 UT, April 11, 2001. The result of a global spatial averaging of $S(t)$ for 403 LOS on the dayside (d). A similar result for 97 LOS on the nightside (e).

The main values characterizing the magnetic storms being analyzed are presented in table II: $D s t$ at the SSC time (according to the data from the GOES satellite); the SSC time; $\max d H / d t$ maximum value of the derivative $H(t) ; \Delta T$ - time interval under investigation; $m$ - number of averagings (of beams) in the case of a global coherent accumulation; $\left|A_{\Sigma}\right|$ - modulus of a maximum response amplitude for the $S(t)$ series (it is shown on a percentage basis how much our measured value of the TEC amplitude differs from the mean background value of $\bar{I}_{0}$ calculated from standard IONEX-files); $\sigma$ - delay between maxima of the series $S(t)$ (inverted values) and 
Table II. Statistics of experiments.

\begin{tabular}{|c|c|c|c|c|c|c|c|c|c|c|}
\hline $\mathrm{N}$ & Date & DST, nT & $\begin{array}{l}\text { Time of } \\
\text { SSC, UT }\end{array}$ & $\begin{array}{c}\max d H / d t, \\
\mathrm{nT} / \mathrm{s}\end{array}$ & $\Delta T$, UT & $\mathrm{m}$ & $\begin{array}{l}\left|A_{\Sigma}\right|, \\
\text { TECU }\end{array}$ & $\begin{array}{c}\sigma, \\
\min \end{array}$ & $\begin{array}{c}\tau, \\
\min \end{array}$ & $r$ \\
\hline 1 & 6.01 .1998 & 102.25 & $14: 16$ & 0.1 & $14-15$ & 395 & 0.1 & -6 & -6.5 & -0.8 \\
\hline 2 & 23.04 .1998 & 148.84 & $18: 25$ & 0.1 & $18-18: 50$ & 401 & 0.1 & \begin{tabular}{|l|}
-3 \\
\end{tabular} & -4 & -0.8 \\
\hline \multirow{3}{*}{3} & & & & & & & $\begin{array}{c}0.4 \\
\bar{I}_{0}=14.5\end{array}$ & & & \\
\hline & 6.04 .2000 & 144.82 & $16: 39$ & 0.2 & $16: 30-18$ & 472 & $2.6 \%$ & -6 & -7 & -1 \\
\hline & & & & & & & $\begin{array}{c}0.1 \\
\bar{I}_{0}=35.3\end{array}$ & & & \\
\hline \multirow[t]{2}{*}{4} & 8.06 .2000 & 114 & $9: 10$ & 0.2 & $8: 55-9: 52$ & 406 & $0.3 \%$ & -3.5 & -4.5 & -0.9 \\
\hline & & & & & & & $\begin{array}{c}0.2 \\
\bar{I}_{0}=35.3\end{array}$ & & & \\
\hline \multirow[t]{2}{*}{5} & 13.07.2000 & 88.32 & $9: 42$ & 0.1 & $9: 19-10: 32$ & 227 & $0.3 \%$ & -3 & -13.5 & -0.9 \\
\hline & & & & & & & $\begin{array}{c}0.1 \\
\bar{I}_{0}=37.3\end{array}$ & & & \\
\hline \multirow[t]{2}{*}{6} & 14.07.2000 & 101.45 & $15: 32$ & 0.1 & $15-16$ & 350 & $0.4 \%$ & -4.5 & -6 & -0.8 \\
\hline & & & & & & & $\begin{array}{c}0.1 \\
\bar{I}_{0}=35.3\end{array}$ & & & \\
\hline \multirow[t]{2}{*}{7} & 15.07 .2000 & 166.5 & $14: 37$ & 0.4 & $14-15: 21$ & 203 & $0.3 \%$ & -9.5 & -10 & -0.9 \\
\hline & & & & & & & $\begin{array}{c}0.2 \\
\bar{I}_{0}=25.9\end{array}$ & & & \\
\hline \multirow[t]{2}{*}{8} & 31.03 .2001 & 143 & $00: 52$ & 0.15 & $00: 22-01: 19$ & 103 & $0.8 \%$ & -4.5 & -7.5 & -0.9 \\
\hline & & & & & & & $\begin{array}{c}0.1 \\
\bar{I}_{0}=39.6\end{array}$ & & & \\
\hline \multirow[t]{2}{*}{9} & 04.04 .2001 & 132 & $14: 55$ & 0.15 & $14: 32-15: 17$ & 91 & $0.2 \%$ & -6 & -3.5 & -0.9 \\
\hline & & & & & & & $\begin{array}{c}0.3 \\
\bar{I}_{0}=35.3\end{array}$ & & & \\
\hline 10 & 11.04 .2001 & 30.6 & $15: 47$ & 0.2 & $15: 30-17: 30$ & 403 & $0.8 \%$ & -9.0 & -51 & -0.9 \\
\hline
\end{tabular}

$d H / d t ; \tau$ - delay between a minimum of the $S(t)$ series and the SSC time; and $\tau$ is the correlation coefficient between $S(t)$ and $d H / d t$.

The distinguishing features of the storms of April 6; June 8, July 15, 2000 and April 4, 2001 are the relatively high maximum values of $d H$ / $d t$ at the SSC time $-0.2,0.4 \mathrm{nT} / \mathrm{s}$, respectively. For these storms, high values of the correlation coefficient of $S(t)$ and $d H / d t,-1$ and -0.9 , were obtained.

It is evident from the table that the global negative TEC disturbance is quite well correlated with the derivative of the magnetic field strength (the correlation coefficient not below -0.8 ) but is delayed with respect to these variations by about 3-9.5 $\mathrm{min}$.

\section{Discussion and conclusions}

Using the new technology for global GPS detection of ionospheric disturbances, GLOBDET, it has been ascertained that a drastic increase in the time derivative of the magnetic field strength at the time of magnetic storms is accompanied by an almost simultaneous 
decrease of the mid-latitude TEC throughout the dayside. The corresponding correlation coefficient is not below -0.8 ; the delay with respect to the time of the sudden magnetic storm commencement is about $3-10 \mathrm{~min}$. This is most pronounced for magnetic storms with a clearly-defined SSC. The amplitude of the «instantaneous» TEC response for the events under consideration was 0.1-0.4 TECU, and the travel velocity of the disturbance from the dayside to the nightside was in the order of $10-20 \mathrm{~km} / \mathrm{s}$. These results are in reasonably good agreement with data obtained by recording the ionospheric response to a sudden commencement of strong magnetic storms, based on measurements of the frequency Doppler shift along a HF path (Huang et al., 1973).

Thus the disturbances which we have analyzed do not fit in the model of AcousticGravity Waves (AGW), and the appropriate physical mechanisms should be pursued when modeling the electromagnetic set of phenomena accompanying a strong geomagnetic disturbance.

Effects caused by electric fields in the ionosphere influence the behavior of its parameters and manifest themselves differently with a different latitude, which is due primarily to the geomagnetic field geometry. Under quiet conditions, the electric field has no marked effect on the behavior of ionospheric parameters as a function of time. However, during magnetic disturbances when the electric field is enhanced significantly (Kozelova et al., 2001), large variations in the height of the $F_{2}$-layer maximum are observed, which can be caused by the vertical component of the $\vec{E} \times \vec{B}$ - drift of ionospheric plasma (Rüster, 1965). According to Bryunelli and Namgaladze (1988), ionospheric effects of magnetospheric electric fields in mid-latitudes are caused by the divergence of the vertical ion flux produced by the horizontal electric field. The electric field-induced transport during a disturbance in the $F_{2}$-region with the $\vec{E} \times \vec{B}$ drift velocity is effective both on day and night. The electric field can reach $10-15 \mathrm{mV} / \mathrm{m}$ in midlatitudes (Ogawa et al., 1975); the unperturbed values of the field are smaller by a factor of 2-3.

The influence of the vertical component of the $\vec{E} \times \vec{B}$ - drift on the height distribution of electron density was investigated by different methods (Tanaka and Irao, 1973). As the $\vec{E} \times \vec{B}-$ drift velocity is virtually independent of the $F_{2}$ layer height, the profile of the electron density distribution is displaced, under the action of the electric field, as a single whole without changing its form substantially (Bryunelli and Namgaladze, 1988). The eastward-directed electric field causes the height of the $F_{2}$-layer maximum to rise, while the westward-directed field is responsible for its lowering. The $h_{m} F_{2}$ variations are quite well correlated with zonal electric field variations, with a small delay, in the order of 20 min, at night and with a still smaller delay during the daytime. $N_{m} F_{2}$ variations at the time of an instantaneous change of the field are poorly pronounced and show up as a decrease in critical frequencies by about 0.1-0.3 MHz. As suggested in Park (1974), such effects corresponded to electric fields with an amplitude of $5-10 \mathrm{mV} / \mathrm{m}$.

Unambiguous interpretation of the ionospheric effects in terms of the action of electric fields in earlier studies was made difficult by the fact that similar effects can also be caused by AGW generated by auroral electrojets during substorms. The deciding criterion for separating the effects of electric fields and AGW is the delay between geomagnetic and ionospheric effects. In the former case, where the influence of electric fields is predominant, the delay is a few minutes (Bryunelli and Namgaladze, 1988; Volkov and Namgaladze, 2001). In the latter case, where ionospheric effects are triggered by AGW, the delay averages 45-60 min (Shashunkina, 1968, 1972; Afraimovich et al., 2000b).

The analysis made in this paper which describes the occurrence of ionospheric effects on abrupt changes of the electric field, and also the data on TEC variations together with $d H / d t$ obtained in this study, point to the penetration of electric fields of magnetospheric origin with typical nonstationarity times of 30-60 min, into the mid-latitude ionosphere during periods of drastic magnetic disturbances.

\section{Acknowledgements}

The author is grateful to N.N. Klimov and E.A. Ponomarev for their encouraging interest in this study and active participation in discus- 
sions. We are grateful to S.A. Nechayev and V.V. Kharchenko for providing data from magnetic observatory Irkutsk. Thanks are also due to V.G. Mikhalkovsky for his assistance in preparing the English version of the $T_{E} X$ manuscript. We greatly appreciate the Referee's efforts to improve the submitted manuscript. This work was done with support from both the Russian foundation for Basic Research 00-05-72026 and RFBR grant of leading scientific schools of the Russian Federation 00-15-98509.

\section{REFERENCES}

AFRAIMOVICH, E.L. (2000): The GPS global detection of the ionospheric response to solar flares, Radio Sci., $\mathbf{3 5}$, 1417-1424.

Afraimovich, E.L., E.A. Kosogorov, L.A. LEONOVICH, O.S. LESYUTA and I.I. USHAKOV (2000a): Instantaneous Response of the Ionosphere to a Sudden Commencement of the Strong Magnetic Storm of April 6, 2000, http://xxx.lanl.gov/abs/physics/0007006.

AFrAIMOVICH, E.L., E.A. KOSOGOROV, L.A. LEONOVICH, K.S. PALAMARCHOUK, N.P. PEREVAlOVA and O.M. PIROG (2000b): Determining parameters of large-scale traveling ionospheric disturbances of auroral origin using GPS-arrays, J. Atmos. Sol.-Terr. Phys., 62, 553-565.

BOWMAN, G.G. (1965): Travelling disturbances associated with ionospheric storms, J. Atmos. Terr. Phys., 27, 12471261.

BuONSANTO, M.J. (1995): A case study of the ionospheric storm dusk effect, J. Geophys. Res., 100, 23,85723,869 .

BryunElli, B.E. and A.A. NAMgaladze (1988): The Physics of the Ionosphere (Moscow: Nauka), pp. 528 (in Russian).

GURTNER, W. (1993): RINEX: the Receiver Independent Exchange Format Version 2, http://igscb.jpl.nasa.gov/ igscb/data/format/rinex2.txt.

Ho, C.M., B.A. IIJIMA, X.P. LINDQWISTER, A.J. MANNUCCI, L. SPARKS, M.J. REYES and B.D. WiLSON (1998): Ionospheric total electron content perturbations monitored by the GPS global network during two Northern Hemisphere winter storms, J. Geophys. Res., 103, 26,409-26,420.

Hofmann-WellenhoF, B., H. LiChtenegGer and J. CoLlins (1992): Global Positioning System: Theory and Practice (Springer-Verlag, Wien, New York), p. 327.

HuANG, Y.-N. and K. CHENG (1991): Ionospheric disturbances at the equatorial anomaly crest region during the March 1989 magnetic storm, J. Geophys. Res., 96, 13,953-13,965.

HuANG, Y.-N., K. NAJitA and P. YUEN (1973): The ionospheric effects of geomagnetic sudden commencements as measured with an HF Doppler sounder at Hawaii, J. Atmos. Terr. Phys., 35, 173-183.

KLOBUCHAR, J.A. (1997): Real-time ionospheric science: the new reality, Radio Sci., 32, 1943-1952.

KozElOVA, T.V., B.V. KozELOV and L.L. LAZUTIN (2001): Electric fields during the substorm according to data from the CRRES satellite, Geomagn. Aeron., 41, 39-49 (in Russian).

MAKAROV, G.A. (1994): Sudden geomagnetic storm commencements and conditions in the solar wind, Geomagn. Aeron., 34, 1-6 (in Russian).

ManNuCCI, A.J., C.M. Ho, U.J. LindQwister, T.F RUNGE, B.D. WILSON and D.N. YUAN (1998): A global mapping technique for GPS-driven ionospheric TEC measurements, Radio Sci., 33, 565-582.

Mullayarov, V.A. and E.O. MuZlOV (2000): SC effects in VLF emission, Geomagn. Aeron., 40, 102-106 (in Russian).

NIELSEN, N. and F. HONARY (2000): Observations of ionospheric flows and particle precipitation following a sudden commencement, Ann. Geophys., 18, 908917.

OGAWA, T., Y. TANAKA, A. HuZITA and M. YASUHARA (1975): Horizontal electric fields in middle latitude, Planet. Space Sci., 23, 825-830.

PARK, C.G. (1974): A morphological study of substormassociated disturbances in the ionosphere, J. Geophys. Res., 79, 2821-2827.

Potapova, N.I. and D.B. ShapIRo (1961): Height distribution of ion density during the June 1959 ionospheric distur-bances, Ionos. Issled., 6, 23-28 (in Russian).

RÜSTER, R. (1965): Height variations of the $F_{2}$-layer above Tsumeb during geomagnetic bay-disturbances, $J$. Atmos. Terr. Phys., 27, 1229-1245.

SHASHUNKINA, V.M. (1968). Ionospheric effect of a sudden magnetic storm commencement in the years of maximum and minimum solar activity, Geomagn. Aeron., 8, 184-187 (in Russian).

SHASHUNKINA, V.M. (1972): Research results on the sudden magnetic storm commencement effect, Ionos. Issled., 20, 154-165 (in Russian).

TANAKA, T. and K. HIRAO (1973): Effects of an electric field on the dynamical behavior of the ionospheres and application to the storm time disturbance of the F-layer, J. Atmos. Terr. Phys., 35, 1443-1452.

Volkov, M.A. and A.A. NAMGALADZE (2001): Influence of the magnetospheric convection electric field on the formation of field-aligned currents of the substorm break-up phase, Geomagn. Aeron., 41, 33-38 (in Russian). 